\title{
Dimensões Políticas e Afetivas do Conceito de Espaço/Lugar: Reflexões a partir de Textos Literáríos do Século XX
}

\author{
Political and Affective Dimensions of the Concept of Place/Space: Reflections \\ departing from 20th Century Literary Texts
}

\author{
Izabel F. O. Brandão \\ Universidade Federal de Alagoas \\ ifob@oi.com.br
}

\begin{abstract}
Resumo
Este artigo, que problematiza a questão do espaço/lugar a partir de uma perspectiva feminista, apresenta resultado de pesquisa sobre autoras contemporâneas (CNPq, 2007-2009) e propõe a contribuir no debate para uma possível revisão conceitual em torno da diferença entre a perspectiva do espaço, que incorpora a geografia física e a do lugar, que inclui a dimensão do afeto. Para além da discussão teórica sobre espaço/lugar, textos literários situados no século XX serão trazidos como evidência, ou seja, como autoras brasileiras e estrangeiras percebem a questão do lugar do afeto e como a dimensão afetiva de um espaço/lugar pode-se tornar política na construção da identidade de personagens femininas.
\end{abstract}

Palavras - chave: Espaço/Lugar; autoria feminina; o corpo e o lugar do afeto/político; feminismo e ecofeminismo.

\begin{abstract}
This essay, which problematizes the place/space question from a feminist perspective, presents results from a research about contemporary women writers (CNPq, 2007-2009), and intends to contribute with the debate for a possible conceptual review regarding the difference between the perspectives of space, which incorporates physical geography, and place, which includes the dimension of affect. Beyond the theoretical discussion about place/space, literary texts dating within 20th century will be taken as evidences of how Brazilian and English-speaking women writers understand the question of the place of affection and how such a dimension of a place/space can become political as concerns the construction of female characters identity.
\end{abstract}

Keywords: Place/Space; women's writing; the body and the place of affection/politics; feminism and ecofeminism. 
Assim como simplesmente não existe lugar sem um corpo, também não existe corpo sem lugar.

Edward S. Casey

A temática do lugar tem sido inspiradora em várias áreas, por essa razão não há como fugir da interdisciplinaridade. A noção de lugar extrapola o geográfico, pois tem uma dimensão que passa necessariamente pelo simbólico e a sua representação pode criar universos que vão desde o uso da palavra ao modo como o corpo é habitado, construído, montado, fabricado, com todas as nuances possíveis. Aqui, cabe esclarecer que 'lugar' e 'espaço' podem ser utilizados de forma intercambiada, sem prejuízo para nenhum dos dois conceitos. Parece mais fácil associarmos, ao primeiro, uma dimensão simbólica e, ao segundo, uma geográfica. Mas esses são conceitos dinâmicos e, no caso de espaço, para a geógrafa feminista Doreen Massey (2007[1994], p.3), há uma "geometria social sempre cambiante de poder e significado". Já a noção de lugar, para essa mesma crítica, quando relacionada ao afeto, carrega algumas dificuldades maiores devido à sua associação a stasis e nostalgia. Particularmente, minha percepção é diferente e segue a visão da ecofeminista australiana Val Plumwood (2002), segundo a qual, abordagens emocionais e críticas ao lugar autorizam a entendermos esses conceitos de forma intercambiada, como dinâmicos e inseridos num contexto político, que pede uma leitura não reducionista. Os exemplos literários que trarei, mais adiante poderão mostrar como isso funciona, de forma mais clara.

O conceito de lugar provocador das reflexões feitas pelo meu grupo de pesquisa ${ }^{1}$, ao longo dos últimos anos (2006-2010), e que aparece nas narrativas estudadas, tem uma definição que, na verdade, desliza e incorpora várias nuances, podendo passar pelo lugar do afeto, 'território de afetividade', que foi o ponto de partida para o estudo do primeiro romance da escritora e poeta caribenha Grace Nichols, Whole of a Morning Sky (1986), e que levou ao estudo de outros romances cuja relação com esse lugar aparece de forma inegável, como é o caso de Kangaroo (1926), do inglês D. H. Lawrence; passa também pelo lugar heterotópico, que envolve os romances Pérolas absolutas (2003), da brasileira Heloisa Seixas, Maru (1971) e A Question of Power (1974) da sul-africana Bessie Head; e passa também pela dimensão política que o conceito de lugar tem, a partir dos dois romances de Head, já mencionados.

A percepção do lugar do afeto surgiu a partir do estudo de Whole of a Morning Sky, ao observar a forma como os corpos das personagens são tratados na narrativa, pelos homens e mulheres cujas atitudes são completamente diversas e opostas. Se, por um lado, mostram um tratamento afetivo, afetuoso, amigável, quando as mulheres estão envolvidas nas situações narradas, por outro, mostra intenso conflito quando são os homens os envolvidos.

O corpo das mulheres nesse romance apresenta-se como um "lugar de conexão vibrante, memória histórica e conhecimento" (ALAIMO, 2000, p.126); não é um lócus estático e sem voz. Já o corpo dos homens busca exercer uma relação de poder, de controle (ou melhor, da falta de controle) e domínio do corpo das mulheres, bem como do corpo político no contexto daquela sociedade caribenha. Essa diferença de tratamento pode ser vista em vários momentos da narrativa e a partir de várias personagens femininas e masculinas. No caso específico desse romance, o corpo de que se fala é o corpo negro, de homens e mulheres. Mas esse lugar também aparece em narrativas onde o corpo não é necessariamente racialmente marcado pela cor da pele. A marca mais específica é a de gênero, que envolve homens e mulheres e, nesse caso, a mais relevante. ${ }^{2}$

As atitudes masculinas no romance são as mais diversas, que vão desde a inveja até a violência cometida por um filho contra a mãe, numa tentativa desesperada de controle do corpo desta. Pela perspectiva feminina, podemos dizer que as mulheres constroem um território de intimidade onde fica claro o lugar da afetividade e da confiança. Mesmo considerando que não há um caráter explícito de sensualidade envolvendo as personagens, pode-se também inferir, nessa situação, o lugar do erotismo como 'uma afirmação da força vital das mulheres', conforme o pensamento ecofeminista de Audre Lorde (1989). O erótico, nesse caso, mostra a referência de intimidade dos corpos femininos de forma harmoniosa. $\mathrm{O}$ olhar de negação ao direito à intimidade é o masculino, do marido (Archie) que, mesmo se sentindo 'dono' de Clara (a esposa), não consegue impedí-la de relacionar-se com quem quer que seja, nem de controlar quaisquer dos seus impulsos à felicidade, ao riso, à alegria de ser, que marca as mulheres de Nichols, tanto em sua poesia quanto na prosa.

Assim podemos dizer que o lugar do afeto para Nichols em relação ao corpo está diretamente relacionado ao ser das mulheres. O corpo pode ser visto como uma casa habitada confortavelmente e as mulheres sentem-se livres para lidar com ele da forma que melhor lhes convier.

Mas o lugar do afeto pode apresentar problemas na sua compreensão, por razões que remetem à ideologia

Izabel F. O. Brandão 
patriarcal de associação do 'afeto' às mulheres, contextualizando-as numa lógica potencialmente reacionária das emoções (MASSEY, 2007 [1994] e McDOWELL, 2007 [1999]). Entretanto, ao aproximarmos o lugar do afeto ao que Val Plumwood (2002, p.233) chama de 'place-sensitivity' (sensibilidade ao lugar), é possível reivindicar abordagens emocionais e críticas a espaço/lugar. Essa relação de sensibilidade ao lugar está diretamente relacionada aos viajantes, pois em cada lugar que vão, buscam organizar o espaço onde estão, temporariamente, instalados de forma a se sentirem 'em casa', ou seja, em 'seu' lugar. É o que ocorre quando viajamos e estamos num hotel, ou similar, e, ao desarrumarmos nossos pertences de viagem no quarto, procuramos sempre organizá-los de modo a nos sentirmos bem nesse espaço estranho e transitório. Cada pequeno objeto colocado num toucador, por exemplo, ou numa mesa de cabeceira vai nos lembrar de um lugar nosso, que nos dá segurança e nos situa nesse espaço, cuja organização é semelhante em qualquer lugar do mundo e que, na visão de Augé (1992), é demarcatório de um 'não-lugar', onde não há referência específica de identidade ou história. É o ser transeunte que organiza temporariamente esse espaço, constituindo provisoriamente uma identidade para si mesmo, tornando esse espaço num 'lugar do afeto', onde pode se reconhecer como sujeito. Essa percepção do 'não-lugar' não está restrita apenas a hotéis, clínicas e hospitais, ou aeroportos, rodoviárias e estações ferroviárias. Pode ocorrer também em outros espaços, onde a pessoa não tem nenhum laço construído, ou esses laços são, por alguma razão, rompidos. ${ }^{3}$

Os estudos sobre a temática do lugar trataram especificamente de autoras, mas foi lendo um autor maldito para as leitoras feministas, o inglês $\mathrm{D}$. H. Lawrence, que foi possível aprofundar a reflexão sobre a constituição do lugar do afeto. ${ }^{4} \mathrm{O}$ romance é Kangaroo (de 1926), escrito na Austrália: seu personagem principal é o escritor Somers que, com sua mulher, Harriet, está temporariamente naquele país, aguardando uma nova viagem. Homem e mulher adotam posturas diferentes acerca do país e da cidade onde estão: em Sidney. A atitude masculina é de total desconfiança do lugar e a sua interação com os habitantes é muito negativa. Mas a personagem feminina, definida como aquela em quem as raízes do escritor estão fincadas é em quem Lawrence deposita o equilíbrio da relação, ainda que temporária, naquele país estranho, onde nenhum dos dois tem qualquer afinidade. Harriet, por já ter vivido em vários países, desde a Inglaterra (de onde foi expulsa com Somers, por causa da primeira grande guerra) à Itália, China e Índia, carrega em seus pertences fragmentos de cada lugar onde morou: uma surrada toalha de mesa, um xale para o sofá, almofadas, pequenos pedaços de afeto que a fazem sentir-se 'em casa', onde quer que esteja com Somers.

Nesse sentido, creio ser possível afirmar, com Massey (2007 [1994], p.169), que "A identidade de um lugar é parcialmente construída a partir de interrelações positivas com outros lugares". Isso é exatamente o que acontece com Harriet, que constrói a sua segurança através da sua organização do espaço/lugar onde está temporariamente vivendo. Esse 'senso de lugar', que a leva a constituir um lugar do afeto na Austrália, é construído a partir da multiplicidade de relações estabelecidas com os outros países onde morou com Somers, traduzidas simplesmente pelo arrumar da casa com os objetos trazidos das outras vivências em diferentes países, sem uma necessária relação de stasis ou 'nostalgia' do lugar onde morou no passado, que poderia assumir uma aparência de conservadorismo ou reacionarismo, ao ser associada às lembranças de um lugar 'perdido', conforme explicita Massey (2007 [1994]), como já me referi. No caso da personagem, a constituição desse lugar produz estabilidade e segurança, algo que todo ser humano quer quando está num território desconhecido, que pode lhe parecer estranho e hostil.

$\mathrm{O}$ romance mostra com clareza o fato de que seus personagens estão fora de lugar e por isso procuram organizar o seu espaço/lugar com a marca do afeto numa busca de segurança, de laços com algo que lhes garanta identidade, que lhes garanta uma referência num território onde não têm raízes (ou identidade). Buell (2005, p.71) afirma que a necessidade de segurança sentida por viajantes, por aqueles fora de lugar, é o que os leva a buscá-la para poder se proteger do 'estranhamento de um lugar estranho', isto é, a constituição de uma identidade provisória torna-se necessária.

O lugar do afeto também pode ser compreendido com clareza no romance Maru, de Bessie Head. Margaret Cadmore, protagonista da narrativa, pertence a uma tribo conhecida como Marsawa, que vive na periferia da vila de Dilepe, em Botswana, ao sul da África, onde a história se passa. Ela é descoberta, por um transeunte, ao lado do cadáver de sua mãe, que morre durante o parto. É educada por uma missionária inglesa, de quem herda o nome. Com essa mulher, aprende a desenhar e a pintar e torna-se professora. Consegue um emprego em Dilepe, mas, ao ser descoberta como Marsawa, passa a ser hostilizada pela comunidade. Isso se reflete na forma como ela passa a ser tratada. Sua exclusão é tanta que até o lugar onde ela passa a morar é vazio, em uma antiga biblioteca. É nesse lugar de exclusão, mas também de construção de

Izabel F. O. Brandão 
conhecimento - é uma biblioteca ainda que vazia - que sua identidade está simbolicamente por ser construída, 'escrita'. Antes de se tornar um lugar do afeto, o lugar pode ser definido de outra forma, pois a biblioteca é também um espaço heterotópico. A heterotopia é definida por Foucault (1984 [1967]) como "lugar de nenhum lugar", e está ligada ao não-lugar, que tem uma conexão mais direta com os corpos físico e psíquico. As heterotopias do tempo constituídas em lugares como bibliotecas e museus, mostram que "o tempo não cessa de se encarapitar no cume de si mesmo" (1984 [1967], p.418). No romance Maru, a biblioteca vazia, mostra um tempo de construção, que é exatamente o que a relação da personagem com o lugar estabelece.

Entretanto, ainda que a personagem ocupe com seu corpo a casa onde mora, esse lugar é vazio. Tal vazio só é preenchido ao aventarmos a possibilidade de liberdade encontrada nos desenhos que ela faz. Isso é o que cria o contexto da dimensão política do lugar, que fica no nível das imensas desigualdades raciais, demarcadas pelo isolamento e desamparo da personagem, a quem é permitido apenas uma espécie de liberdade condicional, no nível do sonho, materializada através dos seus desenhos. Esse lugar político é, nas palavras de MASSEY (2007 [1994]), o lugar/espaço do 'tornar-se', onde tudo pode ser construído, social e simbolicamente falando. O vazio da biblioteca implica efetivamente construção e, nesse caso, leva à falta de raízes da personagem, que não é nada no espaço do outro, pertencente à comunidade de Dilepe, onde ela mora; o seu lugar ainda precisa de alicerces, que ela vai pouco a pouco construindo. É nesse sentido que o seu 'senso de lugar' político, que se associa ao lugar do afeto, passa a ser visto também em relação ao processo de colonização expandido: nessa comunidade colonizada pelos ingleses, os colonizados também agem de forma colonizadora, haja vista que o povo de Dilepe marginaliza, escraviza literalmente, os Marsawa, mantidos à margem, na periferia de Dilepe. O argumento de Bell Hooks (in Massey, 2007 [1994], p. 166), é pertinente: “o próprio sentido de 'lar', em termos de um senso de lugar, tem sido muito diferente para quem foi colonizado; isso pode mudar com as experiências de descolonização e de radicalização". No caso de Margaret Cadmore, ela sofre duplamente: pela colonização inglesa (que ironicamente a salvou) e pela colonização da comunidade de Dilepe, que escraviza seu povo.

Outro aspecto do conceito de lugar foi também estudado através da percepção foucaultiana da heterotopia. Duas autoras estudadas - Heloísa Seixas e Bessie Head - permitem trazer a ilustração mais adequada do não-lugar heterotópico, onde o corpo é fronteira de resistência, conforme discuti em artigos publicados em 2007 e 2009.

No caso de Heloisa Seixas, o lugar heterotópico do corpo aparece a partir do encontro entre a protagonista do romance Pérolas Absolutas, Lídia/Lídice, com a mulher-peixe, um homem/mulher (um/a travesti), cujo corpo 'fabricado' (ZOZZOLI, 2005) - ele/ela tem seios, além do pênis - torna possível que as relações amorosas exerçam sua face obscura e mostrem que a contemporaneidade permite a realização dos desejos sexuais, apesar do perigo que possam representar para a saúde de quem procura um envolvimento com o lado dito marginal da sociedade. A protagonista não se envolve emocionalmente com a mulher-peixe. Realiza apenas um encontro de negócios: ela quer sexo e procura alguém que o tem para vender, mas conhece o perigo desse tipo de relacionamento e está disposta a correr riscos (diz isso textualmente). Por ser bióloga conhece cientificamente a lama, uma vez que lida com a natureza não como essência e sim como um espaço de produção do conhecimento. Por trabalhar no mangue, precisa conviver com tudo o que ele representa. No espaço do real, onde sua vida corre, casa-se com um homem de sexualidade exacerbada, que desapareceu. Todos os episódios posteriores do romance são, na verdade, uma experiência centrada no corpo como lugar heterotópico, que funciona como uma linha de fronteira onde os conflitos são parte do processo de um jogo de espelhos, onde tudo é duplicado (as gêmeas Lídia/Lídice são apenas o ponto de partida), podendo ser percebido a partir da relação de simultaneidade, que é "dependente da escolha de um ponto de referência em movimento" (MASSEY, 2007 [1994], p.3) e o limite corporal é dado pelo desejo sexual que se transforma num desejo social de autodestruição. O lugar do corpo construído nessa narrativa está no conflito trazido pela fronteira e que é enfrentado pela protagonista.

O segundo romance de Bessie Head: A Question of Power, é autobiográfico. A personagem central, Elizabeth, é filha de mãe branca e pai negro, tendo sido dada para adoção, mas devido à sua origem, encontra uma série de dificuldades até ser adotada em definitivo. Desde cedo apresenta sérias crises nervosas e sua vida é um constante ir e vir, de entradas e saídas nas fronteiras do ser. Ela pode-se dizer, vive aprisionada em si mesma e constrói um universo paralelo, onde seres reais são transformados em verdadeiros obsessores e sua vida um inferno psíquico de simultaneidades (no sentido dado por Massey) que a levam a um confronto sobre o espaço/lugar do seu ser. $\mathrm{O}$ corpo da personagem é refém dessas entradas e saídas, de onde Elizabeth só consegue se desvencilhar ao se refugiar no trabalho voluntário, ao lado de um

Izabel F. O. Brandão 
coletivo de pessoas oriundas de vários países e colaborar na manutenção de um 'vegetable garden', nas raras vezes que consegue a posse de si mesma. A luta dessa personagem é calcada nas suas reações de uma vivência de exílio, que marca sua identidade através desse intenso conflito consigo mesma, dos deslocamentos geográficos e psíquicos, dos quais se vê refém: da África do Sul para Botswana e, dentro desse país, para os diversos lugares e vilarejos para onde tem que migrar. Mas, mais do que as migrações espaciais, o seu inferno psíquico é o que demarca o seu não-lugar nessa heterotopia que não lhe permite o controle ou a posse de si mesma.

A complexidade desse romance pede um trabalho específico, mas dada a limitação de espaço neste artigo, optei por apenas fazer referência ao conteúdo heterotópico do jardim, como forma de ilustrar a dimensão utópica do conceito de lugar. Essa dimensão, segundo estudiosos da utopia como J. D. Hunt (1987), por exemplo, mostra que jardins e lugares verdes podem propor, através do discurso, a correção dos erros do mundo. ${ }^{5}$ No caso desse romance, os 'erros do mundo' coligem para a fome na África, o preconceito racial e a soma total dos males que afligem a alma humana, passando pela religião, pelo sexo, pelas dificuldades que cada ser humano tem, especialmente as mulheres, na sua construção identitária. Elizabeth, a personagem, é alguém que foi totalmente transformada numa outsider desde a sua origem na África do Sul, e que encontrou um espaço/lugar para viver, em Botswana, mas encontrar um lugar para viver não significa necessariamente encontrar-se. Esse é o caso da personagem, que após muitas dificuldades, entre elas, uma crise nervosa que a leva à internação em um hospital (outro lugar heterotópico), a perda do emprego de professora e a mudança para o campo, consegue iniciar um processo de cura a partir de seu trabalho voluntário em um vegetable garden ${ }^{6}$, coletivamente trabalhado tanto por pessoas da comunidade de Motabeng quanto por voluntários de outras partes da África, Europa e Estados Unidos.

A internacionalização da comunidade em torno do vegetable garden coletiviza as ações realizadas e traz o mundo para o pequeno espaço circunscrito de um país africano, além de mostrar outra faceta do jardim, que é "o poder de justapor em um só lugar real vários espaços, vários posicionamentos que são em si próprios incompatíveis" (FOUCAULT 1984 [1967], p.418). Esse lugar coletivo no romance traz uma série de informações, desde o comportamento neocolonialista de alguns voluntários estrangeiros, principalmente Camille, uma dinamarquesa, à solidariedade cega de outros da própria comunidade (Kenosi, uma parceira de trabalho de Elizabeth, é assim), ou as trocas interpessoais e de conhecimento entre os companheiros de trabalho (Tom, o americano, em sua relação de amizade com Elizabeth, é assim). Foucault, ao falar desse tipo de jardim, o coloca como o exemplo mais antigo "na forma de posicionamentos contraditórios" (FOUCAULT 1984 [1967], p.418). Esse espaço do romance de Head aponta para uma série de questões políticas, mas a mais importante, a meu ver, está na ideia de que o vegetable garden traz em si a "ilusão ... de uma primavera permanente" (HUNT 1987, p.136). Aqui a 'primavera permanente', que implica nascimento e renascimento, é politizada por Head que transpõe as metáforas para o contexto africano, um lugar já por si só heterotópico, dadas as imensas dificuldades enfrentadas no continente. $\mathrm{O}$ jardim headiano troca as flores de um jardim normal, alimento do espírito antes de qualquer coisa, para um jardim que cultiva comida, alimento para o corpo, num país pobre. Nesse sentido, o espaço/lugar da cura da personagem não poderia estar relacionado com um espaço/lugar tão adequado quanto o vegetable garden, que, como seus similares de flores, faz parte de uma 'heterotopia feliz e universalizante', conforme os termos de Foucault (1984 [1967], p.418). Penso que, nesse sentido, é também possível associar ao contexto heterotópico a dimensão não só do utópico e do político, mas também do afeto, uma vez que só o trabalho no vegetable garden é capaz de permitir a Elizabeth encontrar-se, reconectando-se com o mundo após tanto sofrimento psíquico. Quando se encontra com Kenosi, sua parceira de trabalho, "O mundo volta ao normal novamente" (p.204).

A partir de tudo o que foi dito, torna-se possível afirmar que, se sem corpo não há espaço, esse 'lugar'7 ocupado pelo sujeito pode constituir um espaço, ainda que este lhe possa ser social e culturalmente negado. Isso politiza a discussão sobre o lugar do corpo, pois, se o sujeito ocupa um espaço, isso implica dizer que esse sujeito 'tem', possui um corpo, mas como afirmar a posse desse corpo, no caso do(s) espaço(s) ocupado(s) pelas mulheres (e outros sujeitos) nas costuras hegemônicas de poder?

Tais espaços são poucos, representam quase nada, do ponto de vista político. Assim, talvez seja possível dizer que, como não ocupam espaços hegemônicos, as mulheres 'não possuem um corpo' efetivamente. A posse simbólica desse corpo pertence a quem detém as instâncias de poder e pode determinar papéis sociais, padrões corporais, etc. Ilusoriamente, os corpos parecem pertencer às suas donas, mas no concreto, no espaço do real, é possível dizer que a exploração efetiva dos seus corpos é de quem detém o poder na sociedade. Tal equação pode levar a respostas quase óbvias: a posse dos espaços hegemônicos permite, no

Izabel F. O. Brandão 
mínimo, violentar, explorar, abusar, etc., o corpo e, evidentemente, o ser das mulheres. A ocupação (posse) do corpo, portanto, significa a ocupação do espaço. A posse do corpo é a posse do espaço. É a construção de um 'lugar' do corpo, de um lugar do ser. Certamente, esse lugar não é apenas o lugar do afeto ou o lugar heterotópico. A dimensão política desse lugar é o que deve ser considerado, uma vez que ela incorpora todas as outras. O lugar/espaço é, portanto político, o que implica em agenciamento, mas essa já é outra história...

Aqui é preciso organizar a discussão em função da representação ficcional das mulheres, no sentido de dizer que ela implica um processo de subversão que algumas narrativas de autoria feminina trazem ou podem trazer em suas histórias. Grace Nichols, por exemplo, usa da ironia e do humor em sua poesia para destituir o padrão corporal vigente, conforme já discuti em várias ocasiões. ${ }^{8} \mathrm{O}$ romance Whole of a Morning Sky, por exemplo, produz essa subversão de outro modo, ao não permitir que a violência possa se constituir como um obstáculo de vida. Nesse sentido, o lugar do corpo é do afeto e envolve as mulheres numa espécie de território fechado, talvez um tanto essencialista, mas que mostra a necessidade do afeto para que a posse desse corpo possa ser materializada.

Heloísa Seixas, por sua vez, apresenta a constatação de que o mundo contemporâneo permite a constituição de um lugar do corpo onde cabe tudo. Quem quer correr riscos - físicos e psíquicos enfrenta esse mundo. Talvez desse enfrentamento, um diálogo possa vir a ser construído e daí possa surgir à pérola, filha dos detritos que compõem o mundo contemporâneo e suas heterotopias.

Bessie Head aparentemente não apresenta saídas, ou pontuando de forma diferente, a autora não revela saídas fáceis. As personagens dos dois romances estudados permanecem confinadas a uma espécie de reclusão forçada: Elizabeth, refém de suas crises nervosas de onde entra e sai como se seu corpo não lhe pertencesse. É possível dizer que, em A Question of Power, a presença da natureza exterior, representada pelo vegetable garden, que ela cuida junto a um coletivo de pessoas, é a única saída para a ocupação do espaço/lugar do corpo. Além disso, há o simbólico desse jardim como um lugar onde as pessoas também disporão de igualdade nessa coletividade formada de pessoas de países diversos, que cuidam do alimento da comunidade, mas o atormentado psiquismo de Elizabeth apresenta fissuras e o limite disso está exatamente nas suas entradas e saídas do corpo sem controle de si mesma. No final do livro, as coisas parecem ter sido resolvidas e ela, uma suicida em potencial, agarra-se à visão do coletivo a partir do seu filho Shorty, que joga futebol em frente à janela, que também permite a visão do jardim experimental: "tudo o que ela poderia fazer era apenas ficar parada olhando pela janela e se agarrar à vida" (p.194).

No caso de Margaret, de Maru, a sua condição de excêntrica na comunidade botswanense que escolheu para viver, a leva ao isolamento. O seu lugar do corpo parece ser apenas o mergulho em si mesma, reforçando, talvez, que, para a autora, o ser precisa de lugares alternativos para garantir a sua liberdade (física e psíquica). Mas Head deixa em aberto a possibilidade de construção da liberdade a partir do sonho de seus personagens centrais, Margaret e Maru, uma vez que ambos têm o mesmo sonho. Ela, por sonhar e materializar esse sonho em seus sketches, e ele, o líder (rei) da comunidade de Dilepe, por pensar construir a liberdade dos povos que deverá comandar, em outro lugar, outra comunidade, que seja inclusiva para caber todos. Para tal, abdica de seu posto de futuro rei, casa-se com a Marsawa e desloca-se para outro espaço, aonde a nova comunidade vai se constituir com os moradores de Dilepe que acompanharam o casal. Portanto, a dimensão do coletivo politiza o lugar do afeto, que constrói as identidades headianas.

Para concluir, quero ressaltar a relevância da discussão sobre o lugar/espaço do corpo não só nas narrativas de autoria feminina contemporânea referidas. O romance lawrenciano Kangaroo traz a dimensão do afeto conjugada com a experiência construída, sem atrelá-la à noção de stasis, de nostalgia, que tornaria conservador o conceito de lugar do afeto, o que espero ter mostrado não ser verdadeiro. Os lugares percebidos mostram que o contexto literário não 'inventa' suas histórias do nada; elas são buscadas no contexto do real e transformadas. Os lugares do afeto, os heterotópicos, cuja dimensão política marca a percepção das autoras/es sobre esses lugares/espaços, podem construir para o público leitor um universo efetivamente real.

1 Grupo Grupo Mare\&sal Estudos e Pesquisa Interdisciplinares, registrado no CNPq desde 1997; é vinculado ao Programa de Pós-Graduação em Letras e Linguística e ao Núcleo Temático Mulher \& Cidadania, da Universidade Federal de Alagoas, e tem integrantes de várias áreas do conhecimento: literatura, psicanálise, saúde, serviço social, comunicação social e filosofia.

Izabel F. O. Brandão 
2 Agradeço a Luiz Paulo da Moita Lopes (UFRJ), leitor de um dos meus artigos (BRANDÃO, 2009) sobre o assunto, cujo questionamento acerca de que lugar do corpo se fala, me levou, espero, a esclarecer essa lacuna ao longo deste artigo.

3 Cf. Augé (1992) para maiores esclarecimentos sobre o não-lugar. Esse espaço, apesar de não se constituir identidade ou história dada a sua organização e caráter de provisoriedade, pode ser transformado num 'lugar', com a dimensão do afeto inserida pelo sujeito que ali se encontra. Além disso, acrescento que é possível também compreender o conceito de não-lugar a partir da existência de comunidades periféricas, como favelas, por exemplo, que existem à margem da sociedade; ou a própria rua, em determinados espaços transformados em 'pontos' de encontro de sujeitos marginais, que habitam o nãolugar exatamente pela sua relação de excentricidade com os territórios organizados socialmente para servirem de pontos de encontro, como bares, restaurantes, $\mathrm{h}(\mathrm{m})$ otéis. Os não-lugares estão mais próximos de nós do que imaginamos. Esse foi um dos temas tratados por Elaine Cristina Raposo dos Santos em sua dissertação de mestrado, defendida em maio de 2008 no PPGLL/UFAL, sob minha orientação.

$4 \quad$ O estudo do romance intitula-se "Lawrence's Homeless Hero: an Ecocritical-Feminist Reading of Kangaroo", foi apresentado na 11th D. H. Lawrence International Conference, ocorrida na Universidade de Nottingham, Inglaterra, de 16-21/08/2007 (<http://dhlawrence.org.uk/dh-lawrence-conference.html $>$ ), tendo sido aceito para publicação na D. H. Lawrence Review (ISSN: 0011-4936), em 2011..

\section{Cf. Hunt, 'Gardens in Utopia: Utopia in the} Garden' (in BAKER SMITH e BARFOOT, eds., 1987), p.114-138. A referência é ao 'Speakers' Corner' do Hyde Park londrino, lugar onde o discurso promete corrigir as coisas erradas do mundo, mas de forma geral ilumina a percepção do jardim (vegetable garden) no romance de Hea..

6 'Vegetable Garden' nada mais é do 'horta' em português, mas a dimensão da palavra 'jardim' perde-se na tradução, por isso a minha escolha de manter a palavra no original em inglês e assim projetar a dimensão utópica pertencente a ela.

7 Segundo o ecocrítico Glenn Love (2003), pensadores como E. Casey, J. E. Malpas e D. Abram aliam a noção de lugar ao corpo "na tradição fenomenológica de Edmund Husserl e Maurice
Merleau-Ponty, na qual o primado do mundo vivido da experiência corporal é a fundação para todo o pensamento, significado e comunicação humanos. 'Assim como simplesmente não existe lugar sem um corpo', conforme escreve Edward S. Casey, 'também não existe corpo sem lugar.. [S]omos incorporados ao lugar"” (p.93, grifos originais). No caso da ecologia, Love afirma que "não existe organismo sem um ambiente, ou ambiente sem um organismo" (p.93).

8 Cf. referências ao final deste artigo.

\section{Referências}

ALAIMO, Stacy. The Undomesticated Ground Recasting Nature as a Feminist Space. Ithaca and London: Cornell UP, 2000.

AUGÉ, Marc. Non lieux: introduction à une anthropologie de la surmodernité. Paris: Seuil, 1992. [AUGÉ, Marc. Não-Lugares: introdução a uma antropologia da supermodernidade. Campinas: Papirus, 1994.

BACHELARD, Gaston. The Poetics of Space. London: Beacon Press, 1965.

Gênero e outros lugares: espaços e poéticas interdisciplinares. Maceió: Edufal, 2009.

Dimensões políticas e afetivas do corpo em

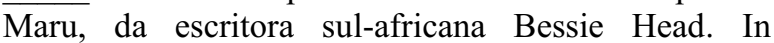
BRANDAO, I. F. O.; ALBUQUERQUE, F. (Org.) . Gênero e outros lugares: espaços e poéticas interdisciplinares. Maceio: Edufal, 2009, p.117-126.

Decolonizing ghosts: gender, the body and violence in Whole of a Morning Sky, by Grace Nichols. Anglistica Aion- an Interdisciplinary Journal, v. 12, p. 101-115, 2008. Disponível em $<$ http://www.anglistica.unior.it/content/decolonizin g-ghosts-gender-body-and-violence-whole-morningsky-grace-nichols> Acesso em: 08 de junho 2011.

Grace Nichols and the body as a poetics of resistance. Revista Englishes - Letterature Inglesi Contemporane. Roma: Pagine, 2007.

Bessie Head: Women's Sense of Place in an African World, 2007 (inédito).

Lawrence's Homeless Hero: an EcocriticalFeminist Reading of Kangaroo, 2007 (inédito). 
O corpo como fronteira do contemporâneo em Pérolas Absolutas, de Heloisa Seixas. In: WOLFF, Cristina Scheibe et al (Org.). Leituras em rede: gênero e preconceito. 1 ed. Florianópolis: Mulheres, 2007, v. 1, p. 191-203.

BUELL, Lawrence. The Future of Environmental Criticism - Environmental Crisis and Literary Imagination. Oxford: Blackwell, 2005.

FOUCAULT, Michel. Outros lugares. In MOTTA, Manoel Barros de (Org.). Michel Foucault - Estética, literatura e pintura, música e cinema. Trad. Inês Autran Dourado Barbosa. Rio de Janeiro: Forense Universitária, 2001 (1984 [1967]), p.411-418.

HEAD, Bessie. A Question of Power. Oxford: Heinemann, 1974.

HEAD, Bessie. Maru. Oxford: Heinemann, 1971.

HUNT, "Gardens in Utopia: Utopia in the Garden". In BAKER SMITH, D. e BARFOOT, C.C. (Org.). Between Dream and Nature: Essays on Utopia and Dystopia. Amsterdam: Rodopi, 1987, p.114-138.

LAWRENCE, David Herbert. Kangaroo. London:, Penguin Books, 1988 [1923].

LORDE, Audre. Sister Outsider: Essays and Speeches. Freedom, CA: Crossing Press, 1984.

MASSEY, Doreen. Space, Place and Gender. Minneapolis: University of Minnesota Press, 2007 (1994).

McDOWELL, Linda. Gender, Identity and Place: Understanding Feminist Geographies. Minneapolis: University of Minnesota Press, 2007 (1999).

NICHOLS, Grace. Whole of a Morning Sky. London: Virago, 1986.

PLUMWOOD, Val. Environmental culture: The Ecological Crisis of Reason. London: Routledge, 2002.

ROSENDALE, Steven. (Org.) The Greening of Literary Scholarship. Iowa: Iowa UP, 2002.

ZOZZOLI, Jean Charles Jacques "Corpos de Mulheres enquanto Marcas na Mídia: recortes”. In BRANDÃO, Izabel (Org.). O corpo em revista: olhares

interdisciplinares. Maceió: Edufal, 2005. p. s/p.

Recebido em 15 de outubro de 2010. Aceito em 06 de março de 2011.

Izabel F. O. Brandão 